\title{
PEMBANGUNAN SISTEM INFORMASI GEOGRAFIS BERBASIS WEB UNTUK KEGIATAN EKSKAVASI SITUS WARISAN BUDAYA INDONESIA (STUDI KASUS: KOMPLEK CANDI BATUJAYA)
}

\author{
Zulhans Ramadhan Maharoesman, Deni Suwardhi, dan Agustijanto Indrajaya \\ Institut Teknologi Bandung \\ zulhans.ramadhan@yahoo.com
}

\begin{abstract}
Abstrak : Indonesia adalah negara yang kaya akan warisan budaya. Saat ini kita mengetahui bahwa dokumentasi mengenai objek arkeologi masih terbatas. Sumber pengetahuan mengenai objek arkeologi yang terdokumentasi seperti foto, sketsa, dan buku hanya sedikit. Ekskavasi merupakan kegiatan yang khas dalam arkeologi, sehingga karena keterkaitannya yang begitu erat antara arkeologi dengan ekskavasi menjadikan ekskavasi layaknya identitas arkeologi. Sistem informasi geografis menyediakan kemampuan untuk menyimpan, menampilkan, serta menganalisa data spasial. Kemampuan ini berperan besar dalam menyimpan data arkeologi yang diperlukan oleh para peneliti dalam membantu proses ekskavasi. WebGIS memiliki keunggulan dalam menyajikan data spasial yang dapat diakses secara lebih mudah tanpa menggunakan bantuan software khusus GIS. Metode dalam menghasilkan sistem informasi berbasis web untuk membantu proses ekskavasi arkeologi memiliki beberapa tahapan. Tahap awal pembangunan WebGIS dimulai dengan pembangunan basis data. Tahapan pembangunan basis data spasial ini meliputi desain konseptual, desain logika, dan desain fisik. Desain basis data yang telah dirancang kemudian diimplementasikan dengan menggunakan bantuan software PostgreSQL/PostGIS. Selanjutnya, untuk membuat tampilan aplikasi ke halaman web, penulis menggunakan Mapserver dan Google Maps API. Dengan dibuatnya WebGIS ini, diharapkan para arkeolog dapat mengakses dan men-update data yang dibutuhkan, sehingga kegiatan ekskavasi dapat berjalan dengan lebih efektif dan efisien.
\end{abstract}

Kata kunci: Basis Data, Sistem Informasi Geografis, Ekskavasi Arkeologi

\begin{abstract}
Indonesia is one of the countries, rich of cultural heritage. In this time, we know that we have limited of archeological object documentation just like photos, sketchs, and books, we just get a little of information if we use just one of that documentation media. Spatial documentation can be made as WebGIS that can represent archeological objects for excavation. Excavation is the specific activity of archeology, so excavation can be called as archeology identity. Geographic Information System that have storing, showing, and analyzing data ability, it can role in storing archeological data that is needed by researcher to help excavation process. WebGIS has advantage in presenting spatial data. WebGIS give such ease for user to access required spatial data, just only need computer and internet connection even without the GIS software itself. The method for developing WebGIS for archaelogical excavation and conservation of archaelogical object has several stages. The stages begin with data acquisition. The next step is the design of spatial database, this step includes conceptual design, logical design and physical design. These database designs then have to be implemented with PostgreSQL and PostGIS software. To create the WebGIS application for excavation we use Mapserver and Google Maps API. By building WebGIS, archeologist can be accessing and updating archeological data so that excavation process can be done efficiently and effectively.
\end{abstract}

Keywords : Database, Geographic Information System, Archaelogical Excavation

\section{Pendahuluan}

\subsection{Latar Belakang}

Arkeologi merupakan cabang ilmu yang mempelajari kehidupan masa lalu melalui bendabenda peninggalan bersejarah. Dalam mendapatkan data arkeologi diperlukan beberapa tahapan, salah satunya adalah kegiatan ekskavasi. Ekskavasi bertujuan untuk mengumpulkan data arkeologi yang awalnya terpendam di dalam tanah menjadi terkenali dan dapat diidentifikasi.

Dalam implementasi di lapangan, kegiatan arkeologi memiliki standar kegiatan yang mutlak harus diikuti. Tahapan tersebut dimulai dari survei dan ekskavasi (pengumpulan data), pengolahan data, pembuatan laporan hingga publikasi hasil penelitian. Dalam pengumpulan data, ekskavasi memiliki peranan yang sangat penting. Menurut bentuknya, sistem terbagi menjadi beberapa jenis. Sistem ekskavasi yang diterapkan dalam penelitian ini adalah Sistem Grid. Pada sistem ini kotak galian digali dengan dimensi panjang dan lebar masing-masing 2,5 meter.

Situs Candi Batujaya secara geografis terletak di wilayah utara Jawa Barat, tepatnya di Kecamatan 
Batujaya, Kabupaten Karawang, Propinsi Jawa Barat. Situs Candi Batujaya pertama kali ditemukan pada tahun 1984 oleh para peneliti dari Universitas Indonesia. Sejak awal ditemukan sampai dengan penulisan karya tulis ini, penelitian tentang Situs Candi Batujaya masih tetap berlanjut. Situs ini memiliki luas area sebesar 5 $\mathrm{km}^{2}$ dengan dimensi panjang dan lebar 2,5 $\times 2 \mathrm{~km}^{2}$. Wilayah objek penelitian Situs Candi Batujaya telah teridentifikasi sekitar 39 situs yang diyakini merupakan bagian dari komplek perca ndian.

Penelitian ini bertujuan untuk membangun suatu aplikasi sistem informasi geografis berbasis web (WebGIS) yang dapat digunakan oleh arkeolog dalam membantu kegiatan ekskavasi. Alasan digunakan WebGIS karena tidak membutuhkan software khusus dalam menjalankannya serta data dapat diupdate setiap saat.

Pembangunan WebGIS membutuhkan beberapa tahapan, salah satunya adalah pembuatan basis data. Pembuatan suatu sistem basis data dapat mendukung optimalisasi dari sistem informasi geografis yang dibuat. Penyimpanan dalam basis data memberikan keamanan serta kemudahan dalam mengaskes data-data arkeologi yang tersimpan.

Sistem informasi geografis merupakan bagian dari kemajuan teknlogi informasi. Salah satu perkembangan di dalam bidang sistem informasi geografis adalah WebGIS. WebGIS adalah suatu sistem yang dapat terhubung ke dalam jaringan internet yang digunakan untuk mengumpulkan, menyimpan dan menampilkan data informasi bergeoreferensi atau data yang mengidentifikasikan lokasi objek tanpa adanya kebutuhan penggunaan software sistem informasi geografis (Painho, Peixoto, Cabral, \& Sena, 2001). Pada umumnya sistem informasi geografis konvensional membutuhkan software khusus untuk dapat mengaksesnya, sedangkan WebGIS memiliki akses data yang lebih mudah karena tidak membutuhkan software khusus tersebut. Sehingga WebGIS dapat diartikan sebagai GIS yang dapat diakses melalui jaringan internet.

Pembangunan aplikasi WebGIS yang dilakukan pada penelitian ini menggunakan software free dan opensource sehingga tidak membutuhkan biaya yang besar. Software yang digunakan seperti Mapserver, PostgreSQL dan PostGIS. Penelitian ini menggunakan Google Maps API untuk menampilkan peta ke dalam halaman web. Visualisasi tampilan halaman web dibuat menggunakan bahasa pemprograman seperti HTML, PHP, dan Javascript.

Dengan dibuatnya aplikasi sistem informasi berbasis web ini diharapkan kegiatan ekskavasi arkeologi pada situs komplek Candi Batujaya dapat menjadi lebih terfasilitasi dengan adanya basis data digital yang menggabungkan data deskriptif dan data spasial atau peta digital. Arkeolog dapat mendokumentasikan serta memperoleh data spasial yang dibutuhkan selama proses pengerjaan ekskavasi secara cepat. Analisis spasial yang tersaji di dalam aplikasi berupa query pencarian kotak galian hingga perhitungan jarak dari suatu titik kontrol ke salah satu kotak galian. Dengan adanya analisis spasial ini, maka proses stake out kotak galian menjadi lebih akurat untuk menghindari overlapping kegiatan pada satu kotak.

\subsection{Tujuan}

Tujuan dari penelitian ini adalah:

1. Membangun database sistem informasi geografis berbasis web untuk kegiatan ekskavasi situs komplek Candi Batujaya

2. Membangun aplikasi sistem informasi geografis berbasis web situs komplek Candi Batujaya yang dapat dimanfaatkan untuk kegiatan ekskavasi arkeologi.

\subsection{Ruang Lingkup}

Objek yang akan didokumentasikan adalah situs komplek Candi Batujaya. Komplek Candi Batujaya terletak di Kecamatan Batujaya, Kabupaten Karawang, Provinsi Jawa Barat. Data dan turunan yang digunakan dalam pembangunan database sistem informasi geografis ini diperoleh dari data pengukuran lapangan dan hasil riset secara langsung oleh tim peneliti Pusat Arkeologi Nasional. Tingkat ketelitian dari sistem informasi geografis ini memuat informasi dari tiap grid utama pada kawasan situs budaya komplek Candi Batujaya. Informasi tersebut diharapkan berguna dalam akses data ketika kegiatan ekskavasi dan pelestarian komplek Candi Batujaya berlangsung.

\section{METODOLOGI}

Kegiatan dimulai dengan analisis kebutuhan sistem, dimana kebutuhan sistem didapatkan dari studi literatur, wawancara ke ahli yang terkait, dan berdasarkan data yang terkumpul selama kegiatan eksvakasi. Proses berikutnya terdiri dari tahapan yang biasa dilakukan dalam pengembangan satu sistem informasi, yaitu desain, implementasi atau kodifikasi, pengujian dan analisis serta membuat resume dari seluruh kegiatan. Desain dibagi dua, yaitu desain struktur data dalam basis data dan desain aplikasi.

Diagram alir pengerjaan penelitian ini adalah sebagai berikut: 


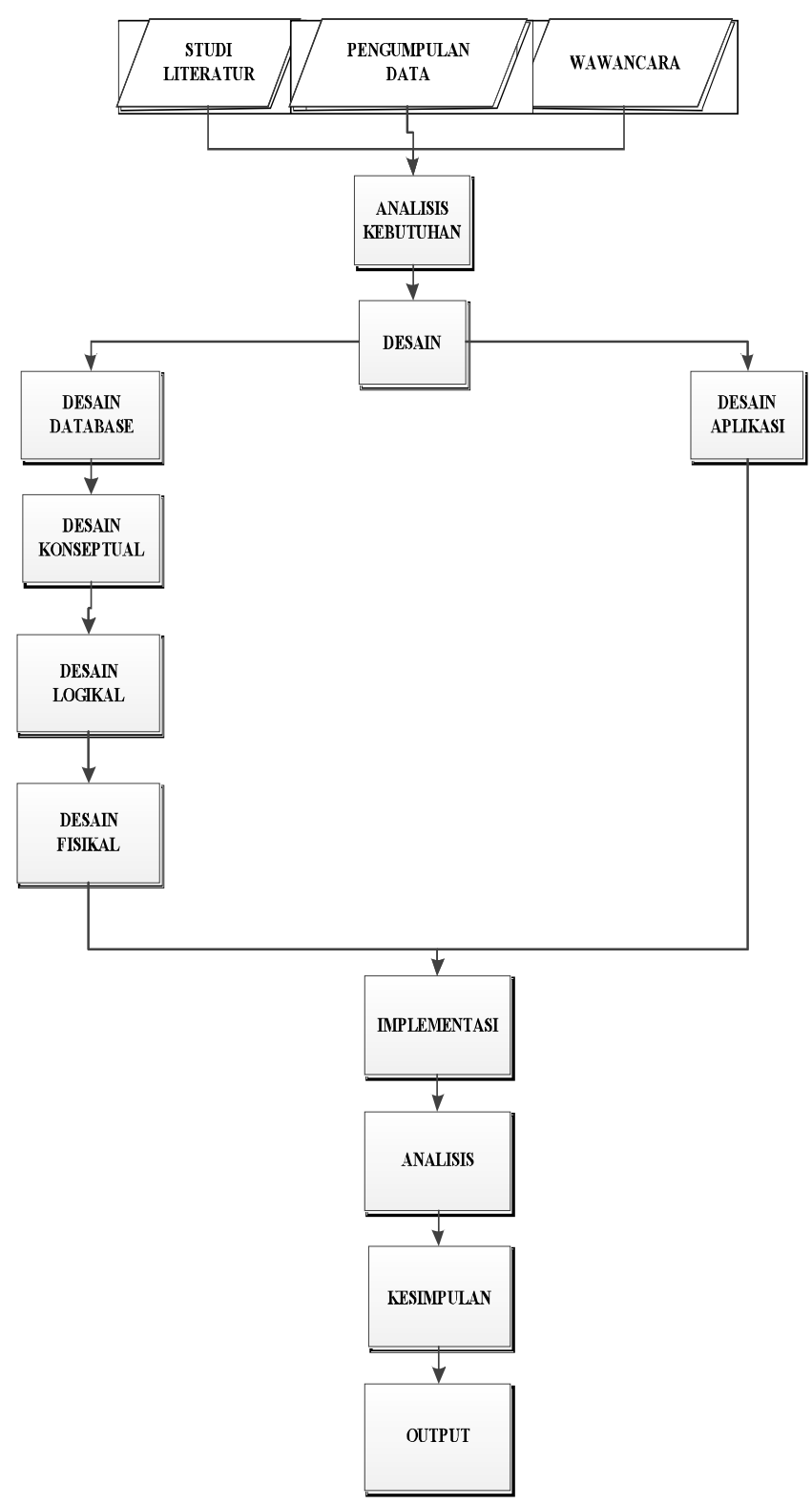

Gambar 1. Metodologi Penelitian

\subsection{Pengumpulan Data}

Data yang digunakan penulis dalam penelitian berasal dari data yang telah diperoleh Pusat Arkeologi Nasional selama pengerjaan ekskavasi situs komplek Candi Batujaya. Data tersebut sebagian besar merupakan data-data arkeologi.

Selain data arkeologi, data yang digunakan dalam pembangunan aplikasi adalah data spasial berupa koordinat control point di sekitar lokasi situs. Akuisisi data telah dilakukan sebelumnya dengan metode foto udara. Pada tahapan selanjutnya, akan terdapat data spasial yang dibuat berdasarkan permintaan pengguna berdasarkan kepada analisis kebutuhan.

\subsection{Analisis Kebutuhan}

Langkah ini bertujuan untuk mengakomodir kebutuhan pengguna atas aplikasi yang dibuat. Pengguna yang dimaksud adalah para peneliti (arkeolog) yang membutuhkan informasi mengenai data arkeologi terkait kegiatan ekskavasi. Informasi yang ingin ditampilkan antara lain :

a. Nomor Input Data

b. Tanggal Input Data

c. Tanggal Kegiatan

d. Sektor

e. Penamaan Kotak Sebelumnya

f. Koordinat Kotak

g. Ketinggian Kotak

h. Deskripsi Stratigrafi

i. Gambar Stratigrafi

j. Gambar Temuan

k. Foto Kotak

I. Foto Temuan Penting

m. Deskripsi Temuan Penting

n. Laporan Kotak

o. Data Pendukung

Sistem informasi geografis berbasis web yang dibuat diharapkan dapat menampilkan grid-grid kerja arkeolog di dalam peta, yaitu kotak galian dengan ukuran panjang dan lebar masing-masing 2,5 meter. Selain itu, diinginkan agar tersedianya grid bantuan yaitu grid dengan skala yang lebih besar $(100 \mathrm{~m} \times 100 \mathrm{~m})$ untuk membantu dalam mencari grid kerja 2,5 meter. Penamaan Grid Kerja pada akhirnya akan memiliki turunan nama pada Grid $100 \mathrm{~m}$.

\subsection{Pembuatan Data Spasial}

Demi terwujudnya keingininan pengguna sesuai dengan analisis kebutuhan, maka dibuatlah data spasial kotak galian arkeologi yang didefinisikan sebagai grid kerja. Grid kerja ini memiliki dimensi panjang dan lebar masing-masing 2,5 meter. Selain data Grid Kerja, diperlukan juga pembuatan data Grid $100 \mathrm{~m}$. Grid $100 \mathrm{~m}$ berfungsi untuk mempermudah pengelompokkan dan pencarian grid kerja pada tampilan web.

Pembuatan data spasial tersebut menggunakan software Global Mapper 13. Gambar 2 adalah contoh hasil tampilan pembuatan Grid $100 \mathrm{~m}$ pada software Global Mapper 13.

Pada setiap satu Grid $100 \mathrm{~m}$ akan terisi 40 baris dan 40 kolom Grid Kerja, sehingga setiap Grid $100 \mathrm{~m}$ akan terdapat 1600 Grid Kerja di dalamnya. Sistem Penamaan grid disesuaikan keinginan pengguna. Penamaan grid kerja merupakan turunan dari penamaan grid $100 \mathrm{~m}$. Alasan sistem penamaan tersebut adalah untuk memberi kemudahan bagi pengguna.

Selain pembuatan data Grid Kerja dan Grid 


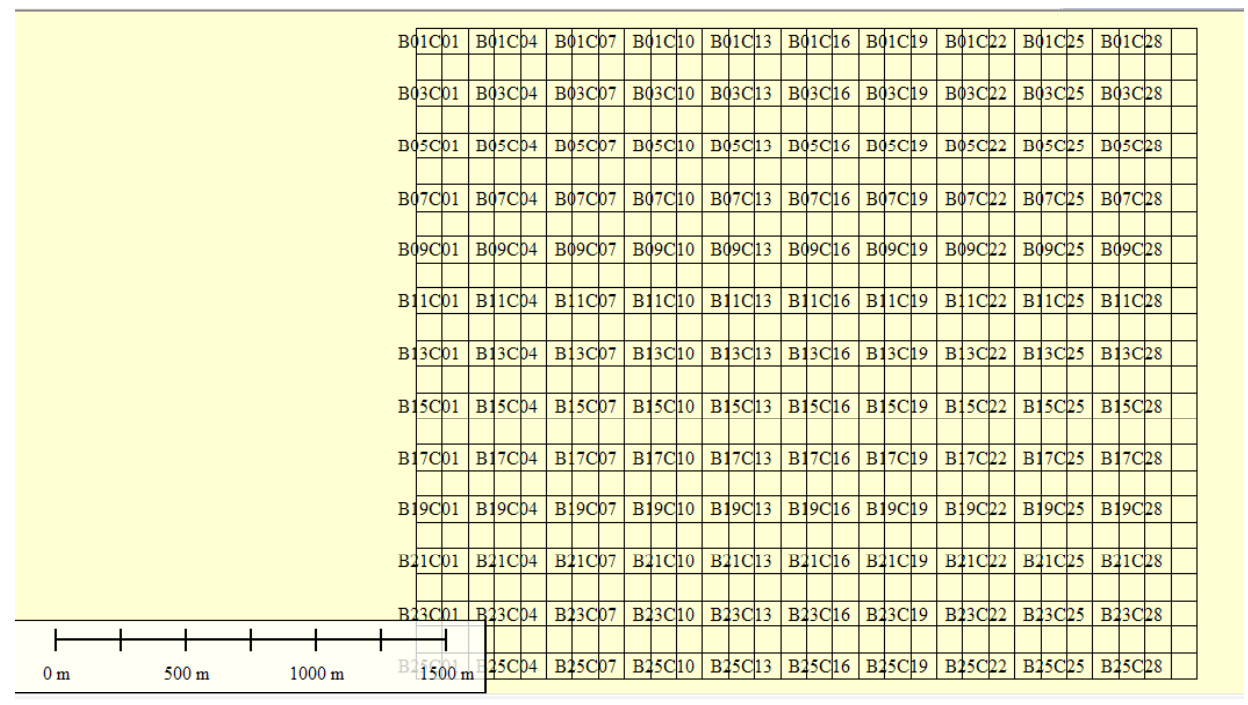

Gambar 2. Hasil Pembuatan Grid 100m

\begin{tabular}{|c|c|c|c|}
\hline & \begin{tabular}{|l} 
gid \\
integer
\end{tabular} & $\begin{array}{l}\text { name_grid } 025 \\
{[\mathrm{PK}] \text { character varying(12) }}\end{array}$ & $\begin{array}{l}\text { name_grid_lokal } \\
\text { [PK] character varying(6) }\end{array}$ \\
\hline 1 & 1 & B15C19_27_29 & U44B 17 \\
\hline 2 & 2 & B15C19_27_30 & U44B 17 \\
\hline 3 & 3 & B15C19_27_31 & U 44816 \\
\hline 4 & 4 & B15C19_27_31 & U 44817 \\
\hline 5 & 5 & B15C19_27_32 & U44B 16 \\
\hline 6 & 6 & B15C19_27_33 & U44B 15 \\
\hline 7 & 7 & B15C19_27_33 & U44B 16 \\
\hline 8 & 8 & B15C19_27_34 & U 44815 \\
\hline 9 & 9 & B15C19_27_35 & U44B 14 \\
\hline 10 & 10 & B15C19_27_35 & U 44815 \\
\hline 11 & 11 & B15C19_27_36 & U 44814 \\
\hline 12 & 12 & B15C19_27_37 & U 44813 \\
\hline 13 & 13 & B15C19_27_37 & U 44814 \\
\hline 14 & 14 & B15C19_27_38 & U 44813 \\
\hline 15 & 15 & B15C19_27_39 & U 44812 \\
\hline 16 & 16 & B15C19_27_39 & U 44813 \\
\hline 17 & 17 & B15C19_27_40 & U 44812 \\
\hline 18 & 18 & B15C19_28_29 & U44B 17 \\
\hline 19 & 19 & B15C19_28_30 & U 44817 \\
\hline 20 & 20 & B15C19_28_31 & U $44 B 16$ \\
\hline 21 & 21 & B15C19_28_31 & U 44817 \\
\hline 22 & 22 & B15C19_28_32 & U 44816 \\
\hline 23 & 23 & B15C19_28_33 & U $44 B 15$ \\
\hline 24 & 24 & B15C19_28_33 & U 44816 \\
\hline
\end{tabular}

Gambar 3 Tabel Basis Data Hasil Overlay

$100 \mathrm{~m}$, penelitian ini juga membutuhkan pembuatan data grid yang mengacu pada datum lokal arkeolog. Grid tersebut mengacu pada suatu datum lokal dengan lebar tiap kotak galian sebesar $5 \times 5$ meter. Data ini kemudian ditransformasi agar sesuai dengan sistem proyeksi yang digunakan dalam penelitian.

Data Grid Lokal dengan Grid Kerja lalu di-overlay dengan menggunakan bantuan software ArcMap 10. Hasil overlay kedua data spasial menghasilkan data atribut yang memiliki hubungan antara keduanya. Gambar 3 menampilkan tabel basis data yang berisi data atribut yang dihasilkan dari operasi overlay layer Grid Kerja dengan Grid Lokal.

\subsection{Perancangan Desain Basis Data}

\subsubsection{Desain Konseptual}

Desain konseptual basis data menggambarkan data yang disimpan dalam database dan hubungan yang terdapat diantara data-data tersebut. Tujuan dari pembuatan desain konseptual adalah untuk menciptakan gambaran sederhana tentang data agar sesuai dengan keinginan pengguna.

\subsubsection{Desain Logika}

Tahapan desain logika menjelaskan kebutuhan yang muncul dari desain konseptual yang telah dibuat sebelumnya. Dalam tahapan desain logika akan ditetapkan ketentuan hubungan antar tabel yang terbentuk dari masing-masing entitas yang dideskripsikan dalam entity rules. Entity rules tersebut akan menjadi dasar dalam pembuatan entity diagram atau Diagram ER.

\subsubsection{Desain Fisik}

Desain fisik merupakan tahap implementasi dari desain logika yang telah dibuat. Pembuatan desain fisik menampilkan perubahan suatu struktur logika menjadi implementasi fisik dalam bentuk tabel pada sistem manajemen basis data. Tujuan dari perancangan desain fisik adalah membuat spesifikasi struktur penyimpanan serta jalur akses data untuk mencapai suatu sistem yang efisien bagi aplikasi.

\subsection{Pembuatan DBMS Menggunakan Software PostgreSQL/PostGIS}

Data spasial yang disimpan pada tabel data spasial pada PostgreSQL adalah data yang memiliki 


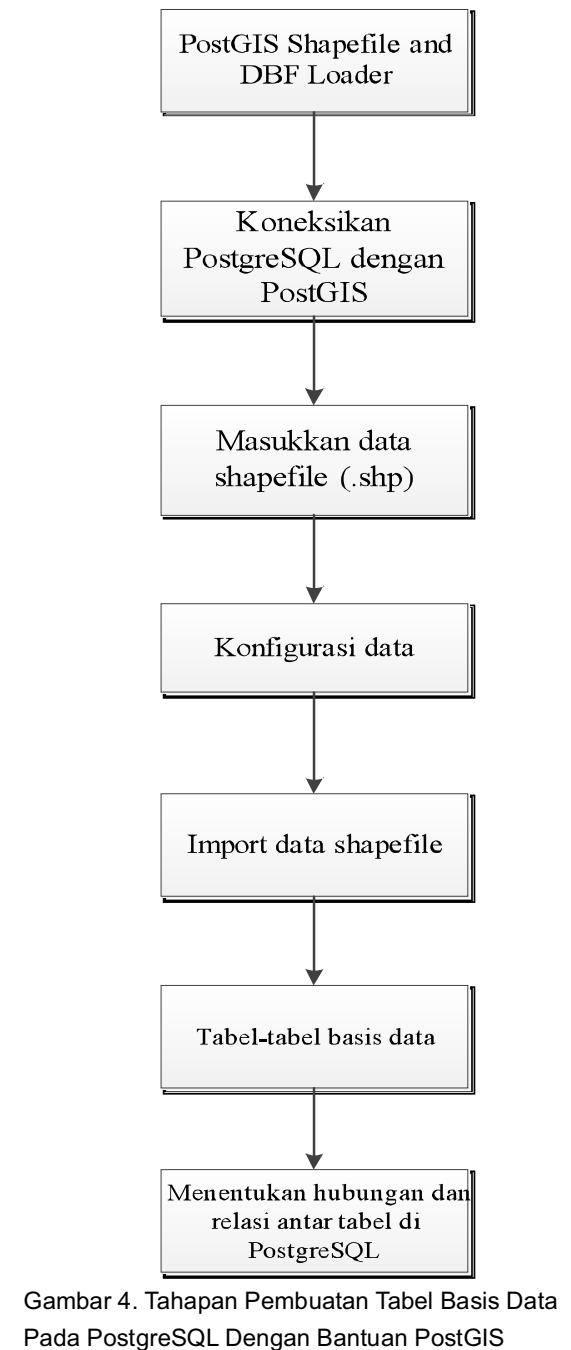

format shapefile (.shp). Format data shapefile memungkinkan untuk disimpan dalam basis data PostgreSQL dengan bantuan software PostGIS. Tahapan pembuatan basis data spasial secara garis besar dapat dilihat dalam diagram alir dibawah ini:

\subsection{Desain Tampilan Aplikasi}

Pada tahapan ini akan dibahas desain-desain tampilan antarmuka dari aplikasi WebGIS. Tampilan antarmuka berfungsi agar interaksi pengguna terhadap aplikasi menjadi semudah dan seefisien mungkin. Prinsip yang digunakan dalam membuat desain antarmuka adalah user-centered design, yang memfokuskan kemudahan bagi pengguna aplikasi. Pembuatan desain tampilan menggunakan bantuan software Adobe Dreamweaver CS5.

\subsection{Konfigurasi Mapserver}

Dalam menampilkan peta yang dihasilkan oleh Mapserver, dibutuhkan dua bentuk file, yaitu Mapfile (.map) dan file HTML (.html). Mapserver akan membaca informasi pada Mapfile (.map) dan

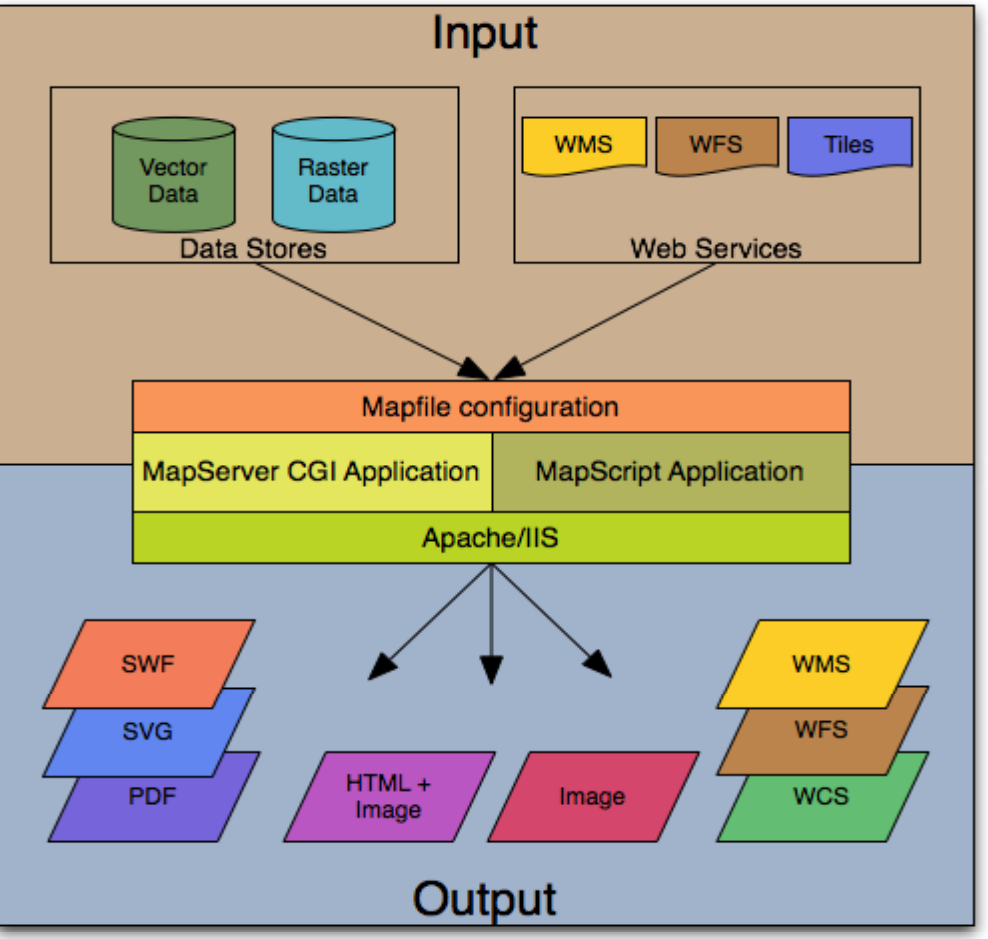

Gambar 5 Arsitektur Konfigurasi Mapserver

menampilkannya ke dalam suatu halaman web dengan menggunakan bantuan webserver. Aplikasi webserver yang digunakan dalam penelitian ini adalah Apache. Mapserver menggunakan beberapa jenis ekstensi sebagai dasar penyusunan tampilan web. Salah satu jenis ekstensi ini adalah mapfile, mapfile merupakan file teks yang berisi konfigurasi dari tampilan yang ingin dihasilkan. Gambar 5 di atas menjelaskan mengenai arsitektur dari Mapserver.

Data spasial yang telah tersimpan pada tabeltabel PostgreSQL/PostGIS selanjutnya ditampilkan menggunakan mapserver dengan memanfaatkan 'OGR Simple Feature Library' yang memberikan akses pada data spasial yang telah tersimpan pada basis data PostgreSQL/PostGIS.

\section{HASIL DAN ANALISIS}

\subsection{Hasil}

Implementasi dari kegiatan ini menghasilkan satu aplikasi yang bisa digunakan para arkeolog untuk mengakses data secara online. Gambar 6 sampai dengan Gambar 10 memperlihatkan tampilan dari aplikasi online tersebut. Aplikasi ini dibatasi penggunanya hanya untuk kalangan tertentu yang berhak untuk bisa mengakses data hasil ekskavasi. 


\subsubsection{Tampilan Halaman Home}

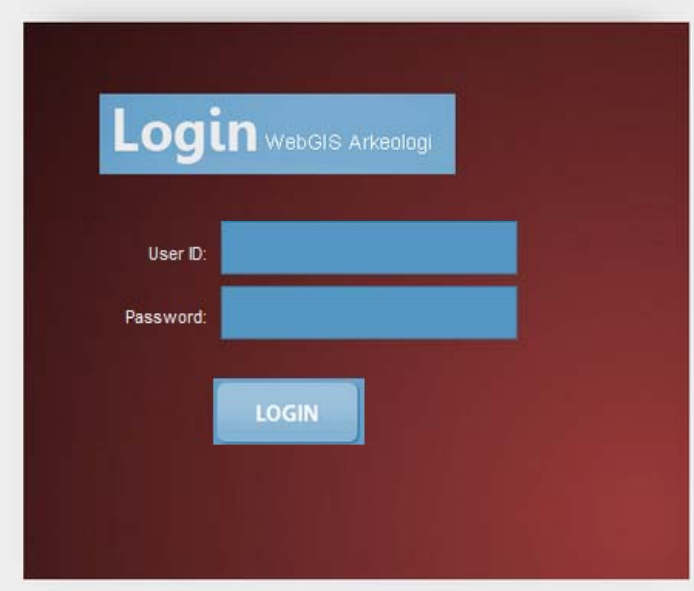

Gambar 6. Hasil Tampilan Halaman Home

\subsubsection{Tampilan Halaman Map (SIG)}

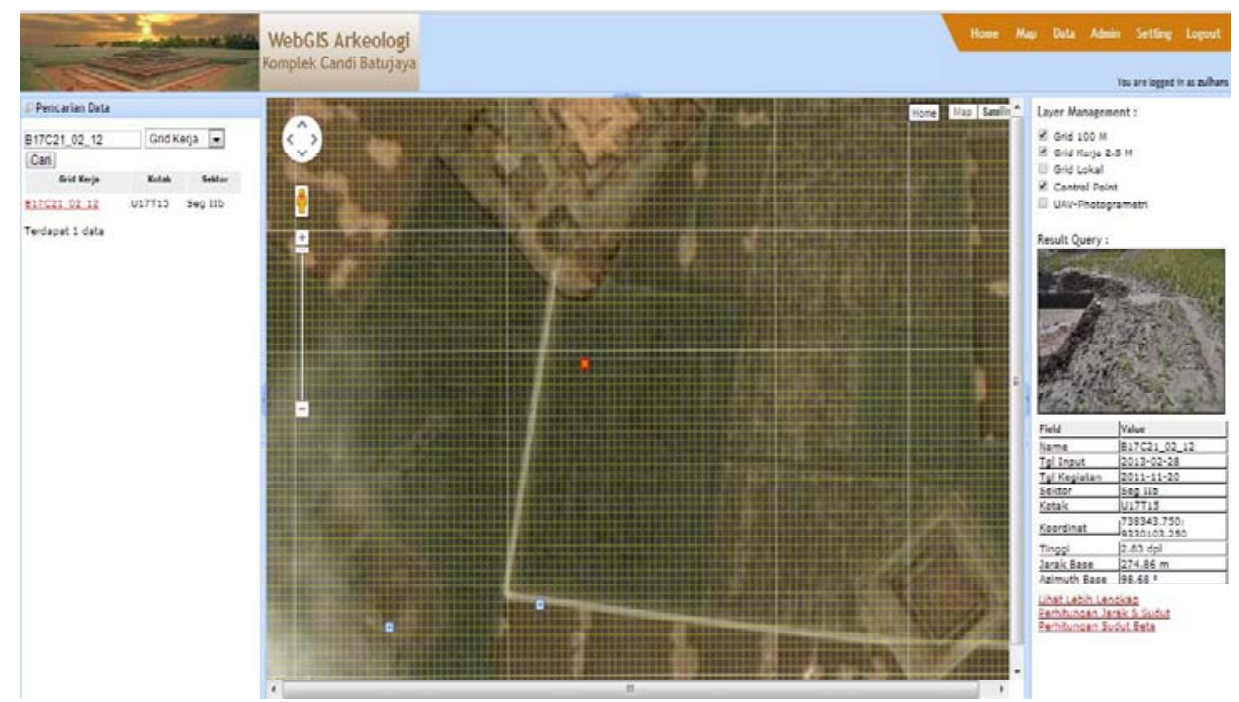

Gambar 7. Hasil Tampilan Halaman Map (SIG)

\subsubsection{Tampilan Halaman Informasi Lengkap Grid Kerja}

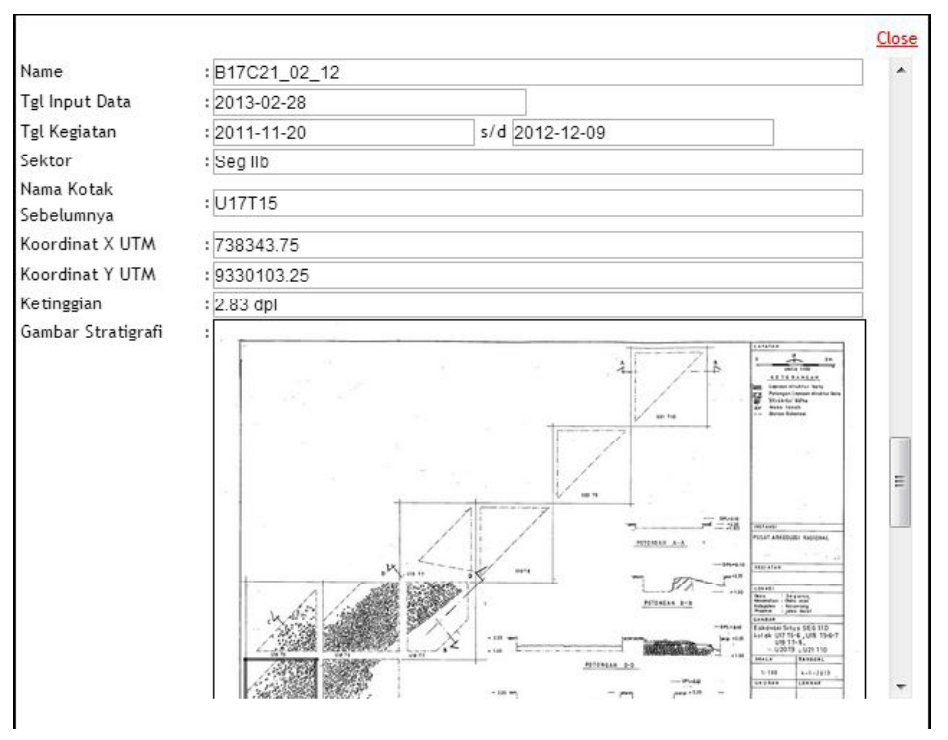

Gambar 8. Hasil Tampilan Halaman Informasi Grid Kerja 
3.1.4 Tampilan Halaman Perhitungan Jarak dan Sudut

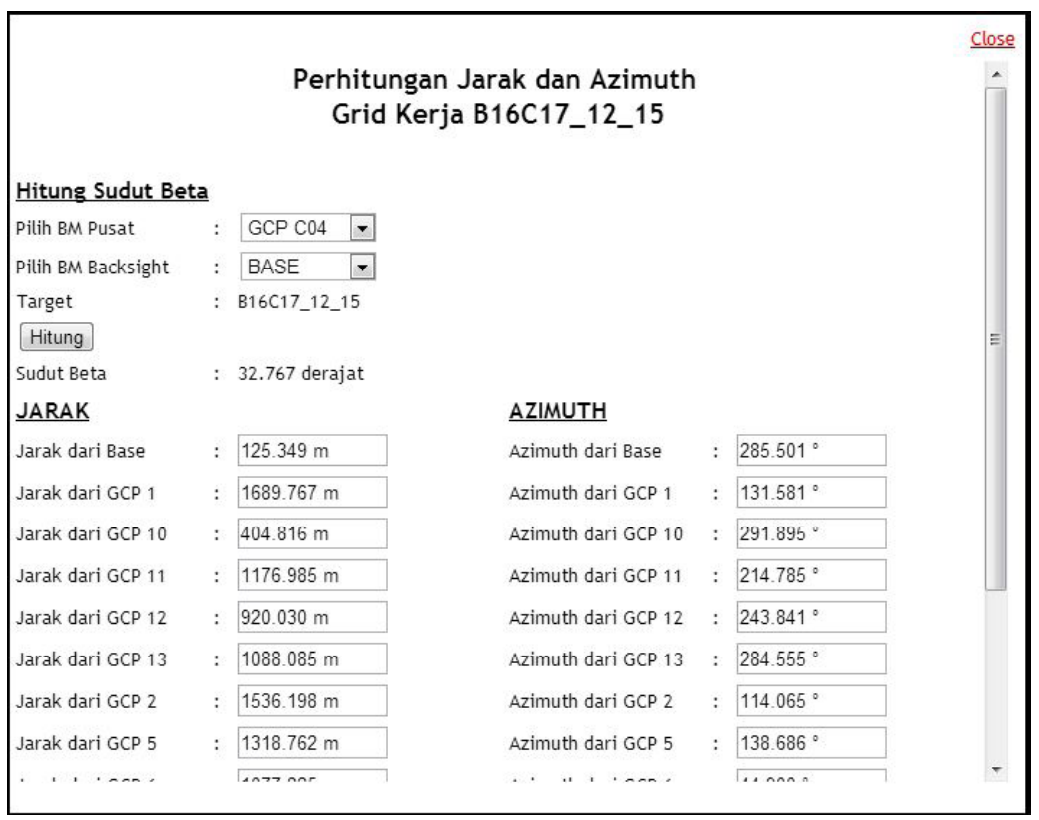

Gambar 9. Hasil Tampilan Halaman Perhitungan Jarak dan Sudut

\subsubsection{Tampilan Halaman Basis Data}

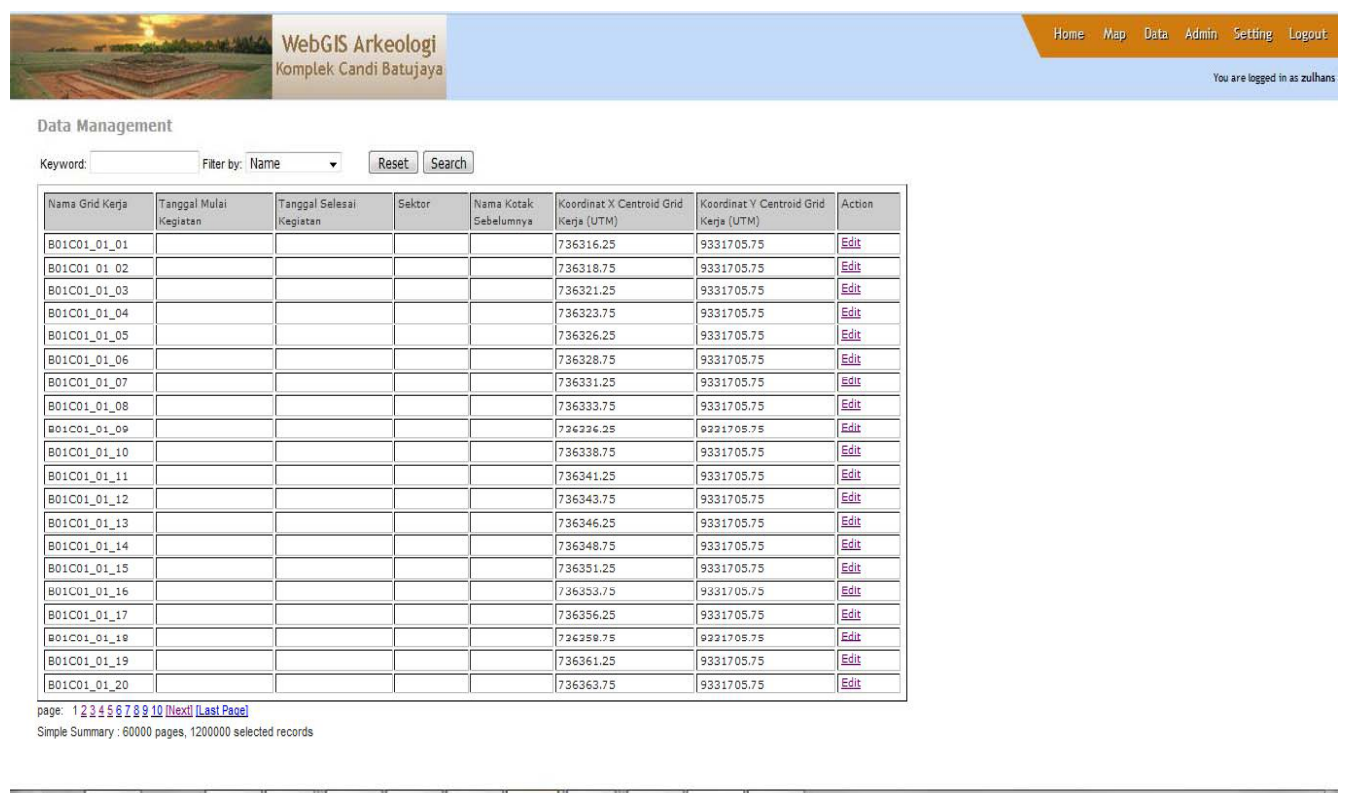

Gambar 10. Hasil Tampilan Halaman Basis Data

\subsection{Analisis}

Berdasarkan proses pembangunan aplikasi sistem informasi geografis berbasis web query yang dibuat, dapat dianalisis beberapa hal sebagai berikut:

- Aplikasi dapat digunakan untuk menyimpan informasi data arkeologi yang dibutuhkan. Data spasial yang disimpan dalam basis data adalah data dengan tipe vektor (.shp) yang sudah memiliki sistem proyeksi dan datum.

- Pengguna dapat memasukkan atau mengubah beberapa isi informasi dari kotak galian (grid kerja) melalui aplikasi tanpa harus masuk ke dalam program sistem manajemen basis data, sebab aplikasi sudah terkoneksi langsung dengan perangkat lunak sistem manajemen basis data PostgreSQL/PostGIS.

- Halaman web mengenai perhitungan jarak dan azimuth yang disediakan oleh aplikasi adalah perhitungan dari control point ke salah satu kotak galian yang dipilih, bukan sebaliknya.

- Koordinat kotak galian (Grid Kerja) yang ditampilkan dalam halaman web merupakan koordinat centroid yang didapatkan melalui proses 
perhitungan data spasial Grid Kerja yang dihitung dengan menggunakan bahasa pemrograman PHP dan SQL.

- Aplikasi sistem informasi berbasis web di dalam penelitian ini sudah dapat melakukan analisis spasial berupa query pencarian data kotak galian serta mencari lokasi kotak galian tersebut di dalam peta. Perhitungan jarak dan azimuth juga merupakan salah satu bentuk analisis spasial yang disajikan oleh aplikasi.

- Tidak semua informasi yang diinput dalam aplikasi akan ditampilkan pada halaman web. Beberapa informasi yang telah tersimpan di dalam basis data hanya dapat dilihat jika mengakses PostgreSQL/ PostGIS.

- Data spasial disimpan pada salah satu kolom atribut basis data PostgreSQL/PostGIS dengan format WKB (well known binary). Namun, data koordinat dapat dimasukkan dalam format WKT.

- Pengguna dapat memasukkan atau mengubah beberapa isi informasi dari grid kerja melalui aplikasi WebGIS tanpa harus masuk ke program basis data, karena aplikasi sudah terkoneksi dengan perangkat lunak sistem manajemen basis data.

- Layer-layer spasial yang ditampilkan menggunakan mapserver adalah layer Grid 100m dan Grid Kerja. Namun, untuk layer control point ditampilkan dengan menggunakan Google Maps API.

- Peta base map disajikan dengan Google Maps API dengan set lokasi di daerah situs komplek Candi Batujaya. Fungsi API menjadikan aplikasi dapat menampilkan peta yang lebih interaktif serta dapat menunjukkan lokasi spasial dari data grid kerja yang dicari.

- Layer UAV-Photogrammetry yang ditampilkan pada halaman web aplikasi hanya berperan sebagai tambahan. Data tersebut tidak memiliki relasi terhadap data-data spasial lain. Data UAVPhotogrammetry memiliki tipe data raster dan tidak disimpan di dalam sistem manajemen basis data. Data tersebut hanya disimpan di salah satu folder arsip dari aplikasi.

- Data mengenai penanggalan yang tersimpan di dalam basis data dengan format (yyyy-mm-dd)

- Aplikasi sistem informasi berbasis web di dalam penelitian ini sudah memiliki tingkatan user untuk dapat mengaksesnya.

- Data yang disimpan pada PostgreSQL/PostGIS terkait dengan data foto (Foto Kotak, Gambar Stratigrafi, Foto dan Gambar Temuan) hanya berupa link URL yang mengacu pada lokasi penyimpanan data karena aplikasi dan basis data belum mampu menyimpan data berformat raster.

\section{KESIMPULAN}

Berdasarkan pembangunan aplikasi sistem informasi geografis berbasis web dalam penelitian ini, dapat disimpulkan beberapa hal sebagai berikut:

- Kegiatan ini menghasilkan suatu aplikasi yang dapat digunakan sebagai media penyampaian informasi ekskavasi bagi arkeolog, khususnya informasi detail mengenai kotak galian, seperti informasi umum kotak, objek temuan yang berhasil ditemukan hingga laporan penelitian mengenai kotak galian tersebut. Aplikasi juga dapat membantu user (arkeolog) dalam memperoleh data spasial yang dibutuhkan dalam kegiatan ekskavasi.

- Aplikasi berhasil membuat suatu sistem basis data dengan menggunakan software opensource PostgreSQL/PostGIS yang berguna dalam kegiatan ekskavasi arkeologi sesuai dengan kebutuhan user. Perancangan desain basis data berhasil diimplementasikan dengan baik dan digunakan sebagai sistem manajemen basis data yang terkoneksi langsung dengan halaman web aplikasi.

- Penggunaan perangkat lunak free dan opensource serperti Mapserver, PostgreSQL/PostGIS dalam pembangunan sistem informasi geografis berbasis web terbukti ekonomis dan tidak kalah unggul dengan perangkat lunak komersil. Penelitian tidak memerlukan biaya yang besar karena source codenya terbuka.

- Aplikasi memiliki kemampuan untuk melakukan perubahan data pada basis data, sehingga user dapat melakukan update data kotak galian secara terus menerus.

- Aplikasi dapat menyajikan tampilan data spasial terkait kotak galian ekskavasi sesuai dengan kebutuhan user. Selain menyajikan data spasial, aplikasi di dalam penelitian ini dapat melakukan analisis spasial sederhana berupa query pencarian data kotak galian serta penentuan lokasi kotak galian tersebut pada halaman web. Analisis spasial lainnya adalah perhitungan jarak dan sudut antara titik control point dengan kotak galian yang dipilih. Fungsi dari hasil perhitungan jarak dan sudut tersebut dapat digunakan oleh arkeolog dalam melakukan stake-out titik di lapangan terkait kegiatan ekskavasi.

- Aplikasi ini sudah memfasilitasi pengguna dalam melakukan analisis spasial seperti query data spasial, perhitungan jarak antar titik dan perhitungan azimuth antar 2 objek. 


\section{Daftar Pustaka}

Aronoff, S. (1989). Geographic Information System: A Management Perspective. Ottawa, Canada: WDL Publication.

Elmasri, R., \& Navathe, S. (2011). Fundamaentals of Database Systems. Addison-Wesley.

Fadinar, M. (2008). Perancangan Sistem Informasi Pasut Berbasis Web. Bandung: Institut Teknologi Bandung.

Fathansyah. (1999). Basis Data. Bandung: Informatika.

Guting, R. (1994). An Introduction to Spatial Database System. Fern Universitat Hagen, Hagen.

Tim Peneliti Pusat Arkeologi Nasional (2012). Awal Sejarah Di Pantai Utara Jawa Barat, Komplek Percandian Batujaya, Kabupaten Karawang, Provinsi Jawa Barat. Jakarta: Pusat Arkeologi Nasional.
Painho, M., Peixoto, M., Cabral, P., \& Sena, R. (2001). WebGIS as a Teaching Tool.

Prahasta, E. (2009). Sistem Informasi Geografis: Konsep-Konsep Dasar. Bandung: Informatika.

Putra, S. (2013). Pembangunan WebGIS Untuk Kebutuhan Eksplorasi Migas. Bandung: Skripsi Teknik Geodesi dan Geomatika.

Yuwono, J. S. (2003). Aspek-Aspek Teknik Ekskavasi Dalam Kerangka Pemahaman Transformasi Data. 